\title{
International Space Station Major Constituent Analyzer On-orbit Performance
}

\author{
Ben D. Gardner ${ }^{1}$, Phillip M. Erwin ${ }^{2}$ and Souzan Thoresen ${ }^{3}$ \\ Hamilton Sundstrand Space Systems International, Pomona, California, 91767 \\ John Granahan ${ }^{4}$ \\ The Boeing Company, Houston, Texas, 77059 \\ and \\ Chris Matty \\ NASA Johnson Space Center, Houston, Texas, 77058
}

\begin{abstract}
The Major Constituent Analyzer is a mass spectrometer based system that measures the major atmospheric constituents on the International Space Station. A number of limited-life components require periodic changeout, including the ORU 02 analyzer and the ORU 08 Verification Gas Assembly. Over the past two years, two ORU 02 analyzer assemblies have operated nominally while two others have experienced premature on-orbit failures. These failures as well as nominal performances demonstrate that ORU 02 performance remains a key determinant of MCA performance and logistical support. It can be shown that monitoring several key parameters can maximize the capacity to monitor ORU health and properly anticipate end of life. Improvements to ion pump operation and ion source tuning are expected to improve lifetime performance of the current ORU 02 design.
\end{abstract}

AR Atmosphere Revitalization

Nomenclature

$\mathrm{CH}_{4}$ methane

CHIT abbreviation for Mission Action Request

$\mathrm{CO}_{2}$ carbon dioxide

ECV electrometer correction value

FOC functional override command

$\mathrm{H}_{2} \quad$ hydrogen

$\mathrm{H}_{2} \mathrm{O}$ water

ISS International Space Station

MCA Major Constituent Analyzer

$\mathrm{N}_{2} \quad$ nitrogen

$\mathrm{O}_{2} \quad$ oxygen

ORU On-orbit Replaceable Unit

$\mathrm{S} / \mathrm{N}$ serial number

VGA Verification Gas Assembly

\footnotetext{
${ }^{1}$ Project Engineer, Hamilton Sundstrand, 2771 N. Garey Ave., Pomona, California 91767.

${ }^{2}$ Software Engineer, Hamilton Sundstrand, 2771 N. Garey Ave., Pomona, California 91767.

${ }^{3}$ Program Manager, Hamilton Sundstrand, 2771 N. Garey Ave., Pomona, California 91767.

${ }^{4}$ Mechanical Systems Design and Analysis Engineer, Environmental Control and Life Support Systems, The Boeing Company, 13100 Space Center Boulevard, Houston Texas. 77059/HB2-40, AIAA Associate Fellow.

${ }^{5}$ Atmosphere Revitalization Subsystem Manager, EC6 ISS ECLSS, NASA Johnson Space Center, 2010 NASA Boulevard, Houston, Texas 77058.
} 


\section{Introduction}

$\mathrm{T}$

HE Major Constituent Analyzer (MCA) is a mass-spectrometer-based system designed to monitor nitrogen $\left(\mathrm{N}_{2}\right)$, oxygen $\left(\mathrm{O}_{2}\right)$, carbon dioxide $\left(\mathrm{CO}_{2}\right)$, methane $\left(\mathrm{CH}_{4}\right)$, hydrogen $\left(\mathrm{H}_{2}\right)$ and water vapor $\left(\mathrm{H}_{2} \mathrm{O}\right)$ in the atmosphere of the International Space Station (ISS). It is the primary resource for ensuring that the $\left(\mathrm{O}_{2}\right)$ and $\left(\mathrm{CO}_{2}\right)$ levels in the ISS atmosphere are maintained at safe levels, and the $\left(\mathrm{N}_{2}\right)$ partial pressure reading is used to monitor the ISS for cabin air leakage.

The MCA, shown in Figure 1, is designed as a set of seven On-orbit Replaceable Units (ORUs) that can be serviced or replaced individually in response to periodic maintenance requirements. The modular design approach optimizes logistical support to provide service on limited-life components without having to change out the entire MCA. Of these ORUs, ORU 08 (Verification Gas Assembly) and ORU 02 (Mass Spectrometer Analyzer) are the more commonly replaced subsystems. ORU 02 is the mass spectrometer analyzer that forms the technological core of the MCA. It is comprised of a gas inlet, an ion source, a single-focusing magnetic sector mass spectrometer, six spatially arrayed ion detection electrometers, associated electronics, and a $4 \mathrm{~L} / \mathrm{sec}$ ion pump. The primary lifelimiting items include the ion source filament (of which there are two) and the ion pump. Considerable attention is being paid to determining the factors limiting both the ion pump and ion source lifetimes, as has been described previously ${ }^{1-4}$. To date, the ion pump has been the driving issue for ORU 02 periodic replacement; however, reductions in gas flow and improved operation of the ion pump, implemented under CR10773A, are expected to increase ion pump time. The effect of reduced gas flow on optimal ion source tuning is currently under investigation and will be reported at a later date.

This paper reports the lifetime and performance characteristics of the most recent ORU 02s used in service since our last report in $2010^{1}$, as well as the performance of ORU 08. Two ORU 02s experienced premature on-orbit failures, which are the subject of a separate investigation. However, two other ORU 02s have exhibited nominal performance. Review of performance data from these ORU 02s suggests that recent ORU 02 design changes have been successful in increasing ORU life.

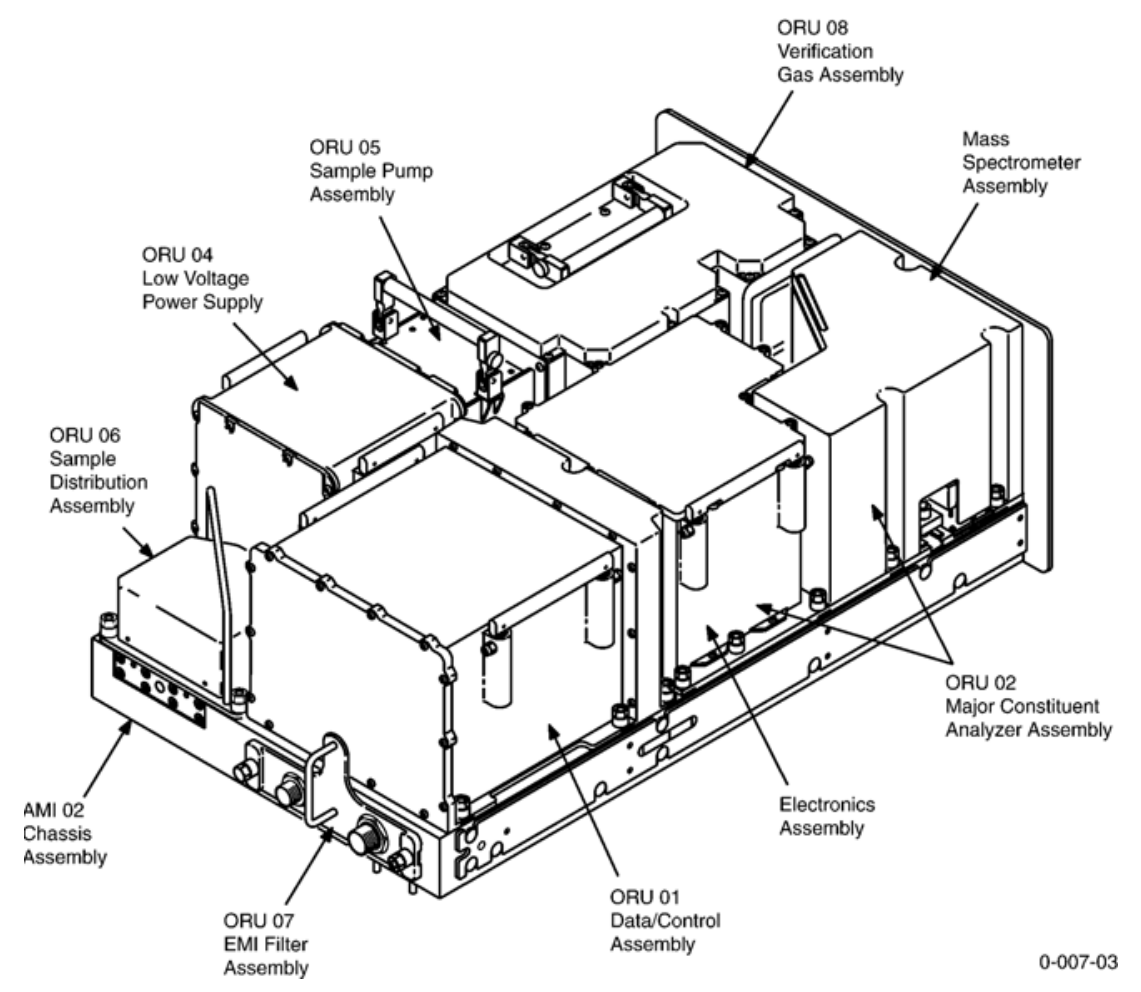

Figure 1: Major Constituent Analyzer 


\section{On-orbit Activities}

\section{A. MCA Transitions On Station}

MCA on-orbit activity was last reported at the 2010 ICES Conference $^{1}$. At that time, Atmosphere Revitalization Rack \#2 (AR2), containing a second MCA, had been delivered on orbit. AR2 was intended for Node 3 but was temporarily installed in the US Lab to take advantage of its new CDRA until ISS Node 3 was delivered on orbit. Atmosphere Revitalization Rack \#1 (AR1), the US Lab AR Rack, had been deactivated and moved to the JEM where it remained dormant for some time.

When AR2 was launched in 2009, it was launched without an ORU 01 Data/Control Assembly in its MCA. ORU 01 serial number F0001 was retained on the ground for installation of new firmware and was planned to launch at a later date. To facilitate the full utilization of AR2, ORU 01 Q0001 was removed from the inactive MCA in AR1 and installed in the MCA in AR2. This MCA was then activated, and improved accuracies were implemented in November 2009.

ISS Node 3 was launched on STS-130 (20A) in February 2010, but the AR Racks were not moved until September of that year. ORU 01 F0001 with new firmware was launched on STS-131 (19A) in April 2010 and installed in the Lab MCA in the dormant AR1. AR2 (with MCA having ORU 02 Q0001) was moved to its intended location in Node 3 on 9/7/10 and activated on that date. AR1 with its MCA having ORU 02 F0003 and ORU 01 F0001 with new firmware was installed in the US Lab and activated on 9/13/10.

Current status of the AR Racks is as follows. AR1 is inactive in the US Lab because of loss of 1553 communication problems with ORU 01 F0001 and premature filament failures with both ORU 02 F0003 and subsequently with ORU 02 F0001. AR2 is active in Node 3 with ORU 01 Q0001 and ORU 02 F0005 installed. ORU 02 F0005 replaced ORU 02 Q0001 in January 2012.

\section{ORU 02 Performance Metrics}

\section{A. Calibration Stability}

ORU 02 analytical stability can be evaluated by tracking the calibration over time. Each ORU 02 is calibrated on the ground to determine its gain characteristics for the detection of each of the major atmospheric constituents. This calibration is based on the response to a verification gas mixture of known, very accurately controlled composition. The resulting calibration values are then programmed into the ORU 02 prior to its protoflight acceptance testing. Ideally, if the performance doesn't change, each ECV should stay at or close to a value of 1.0000; however, it is known that the gain can change slightly over time for various reasons. Consequently, once on orbit, the ORU 02 is calibrated periodically using the same verification gas mixture. Any change in gain value is compensated for by taking the ratio of the expected response (partial pressure of each calibration gas constituent) to the measured response (MCA calculated partial pressures for each constituent) and using that value as a computational correction factor - the Electrometer Correction Value (ECV). The ECVs are used to adjust the result of MCA partial pressure calculations so that the MCA readout remains calibrated against the known composition of the calibration gas mixture. Experience has shown that the absolute value of ECVs may change with time, but the critical factor is that the ECVs do not change significantly with respect to each other. For trending purposes, the ECVs are "normalized" (i.e., each ECV is divided by the weighted ECV of the three most abundant gases $\left(\mathrm{N}_{2}, \mathrm{O}_{2}\right.$ and $\left.\mathrm{CO}_{2}\right)$.

\section{B. Ion Pump Current Trending}

The ORU 02 ion pump is responsible for maintaining the operational vacuum level of the analyzer, and its degradation over time is historically the primary factor that limits the useful longevity of an ORU 02. Ion pump current is a measure of the gas pumping load and, therefore, analyzer pressure. It is typically 60 to $100 \mu$ Amps at the start of its operating life. In the absence of any parasitic shunt currents that occur as the pump ages, a high ion pump current is indicative of a high pressure internal to the analyzer. The vacuum level of the ORU 02 analyzer must be maintained low enough to prevent having the source ionization filaments burn out too quickly, so the MCA is configured to automatically 'safe' the analyzer and protect the filaments when the ion pump current reaches 370 $\mu$ Amps. At this point the MCA generates an error code and goes to FAIL state (i.e., shuts down). Since the ion pump current is a function of both the gas load and the effects of ion pump wear, the base pump current increases over time and the margin between this current and $370 \mu$ Amps is reduced, eventually leading to ion pump end of life.

\section{Filament Current Trending}

Copyright (c) 2012 Boeing. All rights reserved. 
The ORU 02 ion source contains two filaments which generate the electrons used to create electron ionization (EI) derived ions from the gas molecules. ORU 02 normally uses Filament 1 until it is nearly completely consumed or fails, at which point MCA directs the use of the backup filament, Filament 2. Filament performance is monitored using a filament current sensor upstream in the filament control circuitry, reading the current of the primary of a transformer. The filament current sensor reading (FCS01) normally starts at a reading of 120-150 mAmps when a filament is new ( 135 mA is typical), and gradually decreases over time. The slope of a plot of FCS01 gradually becomes more negative until the value reaches about $100 \mathrm{~mA}$, after which it rapidly becomes steeper and the filament fails shortly thereafter. On-orbit practice is to switch from Filament 1 to Filament 2 when FCS01 decreases to about $108 \mathrm{~mA}$, so that Filament 1 can be retained as a backup to Filament 2 should that filament fail during an essential activity on orbit.

\section{Historical ORU 02 Performance}

The historical performances of the ORU 02s that have been used on orbit are listed in Table 1 . The performance lifetimes of these ORU 02s has varied from less than a year to nearly 3 years. The primary failure mode has been the result of the ion pump reaching end of life, although several ORU 02s have been replaced earlier to accommodate other on-orbit activity. More recently, two ORU 02s were replaced due to ion source issues discussed briefly below. It is expected that the implementation of modifications to the ion pump operation, as well as adjustments to initial ion source tuning will yield greater durability of future ORU 02 s. 
Table 1: ORU 02 on-orbit usage.

\begin{tabular}{|c|c|c|c|c|}
\hline $\begin{array}{c}\text { ORU } 02 \\
\text { Serial } \\
\text { No. }\end{array}$ & Activated & Deactivated & $\begin{array}{c}\text { MCA } \\
\text { Serial No. }\end{array}$ & Comments \\
\hline F0001 & $2 / 12 / 01$ & $6 / 23 / 01$ & F0001 & \multirow{2}{*}{$\begin{array}{l}\text { Insufficient operating time to } \\
\text { accumulate life data. }\end{array}$} \\
\hline F0004 & $6 / 23 / 01$ & $4 / 25 / 02$ & F0001 & \\
\hline F0003 & $9 / 1 / 02$ & $9 / 29 / 04$ & F0001 & $\begin{array}{l}\text { Failed (end of life) with high ion } \\
\text { pump current in September } 2003 . \\
\text { Used in life extending mode until } \\
\text { removal in September } 2004 .\end{array}$ \\
\hline F0002 & 9/30/04 & 2/16/06 & F0001 & $\begin{array}{c}\text { Replaced due to increasing } \\
\text { frequency of bad zero calibrations. }\end{array}$ \\
\hline F0001 & $3 / 6 / 06$ & $12 / 28 / 08$ & F0001 & $\begin{array}{l}\text { Operated } 33 \text { months. Removed } \\
\text { before end of life to minimize impact } \\
\text { to on-orbit operations. }\end{array}$ \\
\hline F0004 & $1 / 2 / 09$ & $9 / 22 / 09$ & F0001 & $\begin{array}{c}\text { Operated } 9 \text { months. Had one } \\
\text { shutdown due to high ion pump } \\
\text { current spike. Was replaced before } \\
\text { failure in order to minimize impact } \\
\text { to operations. }\end{array}$ \\
\hline Q0001 & 9/25/09 & $1 / 23 / 12$ & Q0001 & $\begin{array}{l}\text { Operated } 19 \text { months on orbit. High } \\
\text { ion pump current. Replaced prior to } \\
\text { end of life. Currently serving as on- } \\
\text { orbit spare } \\
\end{array}$ \\
\hline \multirow{2}{*}{ F0003 } & $9 / 13 / 10$ & $10 / 8 / 10$ & \multirow{2}{*}{ F0001 } & $\begin{array}{l}\text { Premature failure of Filament \#1. } \\
\text { Operated 9/13/10 - 10/8/10 w/ new } \\
\text { ORU } 01 \text { F0001 and CSCI } 4.24 .\end{array}$ \\
\hline & $5 / 13 / 11$ & $6 / 6 / 11$ & & $\begin{array}{c}\text { Operated 5/13/11-6/6/11 w/ ORU } 01 \\
\text { Q0001 and CSCI 4.18. Filament } 2 \\
\text { failure. }\end{array}$ \\
\hline F0001 & $7 / 6 / 11$ & $7 / 16 / 11$ & F0001 & Premature filament failures. \\
\hline F0005 & $1 / 28 / 12$ & - & Q0001 & Currently in service \\
\hline
\end{tabular}

\section{Recent ORU 02 Performance}

\section{A. ORU 02 Q0001 Performance}

ORU 02 Q0001 was initially activated on 9/25/09 after AR2 was installed in the US Lab. It ran in that location until 9/7/10 (347 days) at which time it was deactivated and AR2 was relocated to Node 3. ORU 02 Q0001 was reactivated in the Node 3 location (AR2) on 9/7/10. A plot of normalized ECVs for ORU 02 serial number Q0001 is shown in Figure 2. Since the MCA, with its currently installed firmware does not measure water vapor accurately, water vapor ECV is not included in this figure. Each of the data points in Figure 2 reflects data from a calibration of the MCA. Examination of the figure reveals that the normalized ECVs, especially those for $\mathrm{N}_{2}$ and $\mathrm{O}_{2}$, the most abundant gases, show very little variation from calibration to calibration and over the entire life of the ORU indicating that the MCA is very stable and accurate. The ECV trend for this ORU 02 was typical of previous ORU 02s used on orbit. 


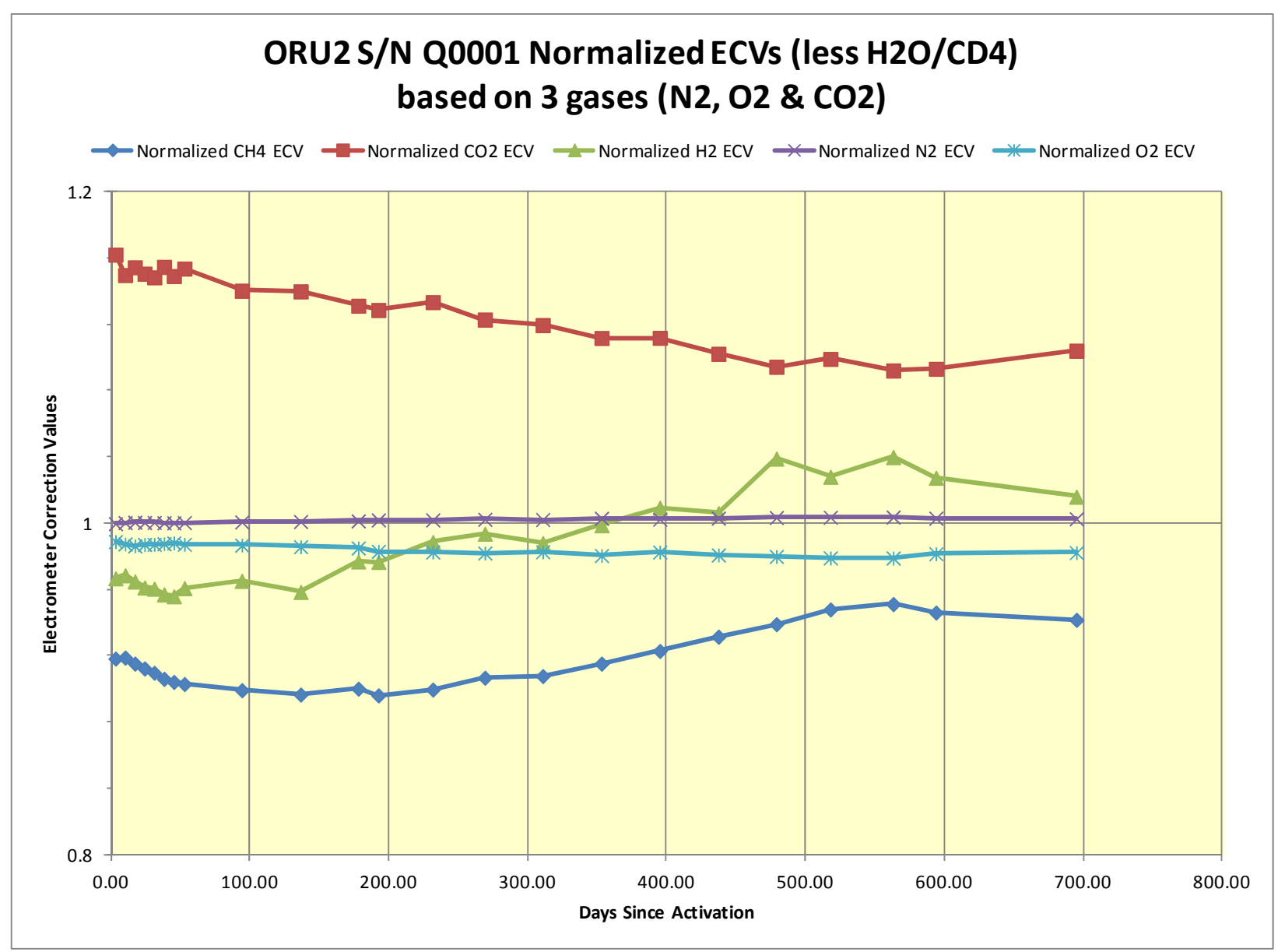

Figure 2: ECVs for ORU 02 Q0001

Although the performance of this ORU 02 was typical from an accuracy standpoint, its ion pump current was higher than typical for most ORU 02s. A plot of ORU 02 Q0001 ion pump current is shown in Figure 3. The initial current on installation was approximately $50 \mu \mathrm{A}$. The MCA experienced two shutdowns in April and May of 2011 due the MCA firmware's high ion pump current fault limit being exceeded. This raised concern that ORU 02 was nearing the end of its operational life. Also in May 2011, a leak of calibration gas from the Verification Gas Assembly (serial number Q0001) was experienced. A manual valve in the Verification Gas Assembly was closed to preclude further leakage. This made it necessary to have the crew open the manual valve before each calibration and close it immediately thereafter. Because of this inconvenience and in order to conserve as much life of the ORU 02 as possible, a decision was made to deactivate the MCA as of 5/13/11. On 8/17/11, the MCA was reactivated in "Life Extending Mode" (LEM) to allow occasional use to check ISS atmosphere partial pressures. In LEM, the ion pump is operated to maintain mass spectrometer vacuum, but sample gas flow to ORU 02 is shut off. Without sample gas flow, the ion pump operates at very low current levels, thus conserving ion pump life. Once in LEM, the MCA can be returned to normal operation periodically with minimal effort to read ISS atmosphere partial pressures. 


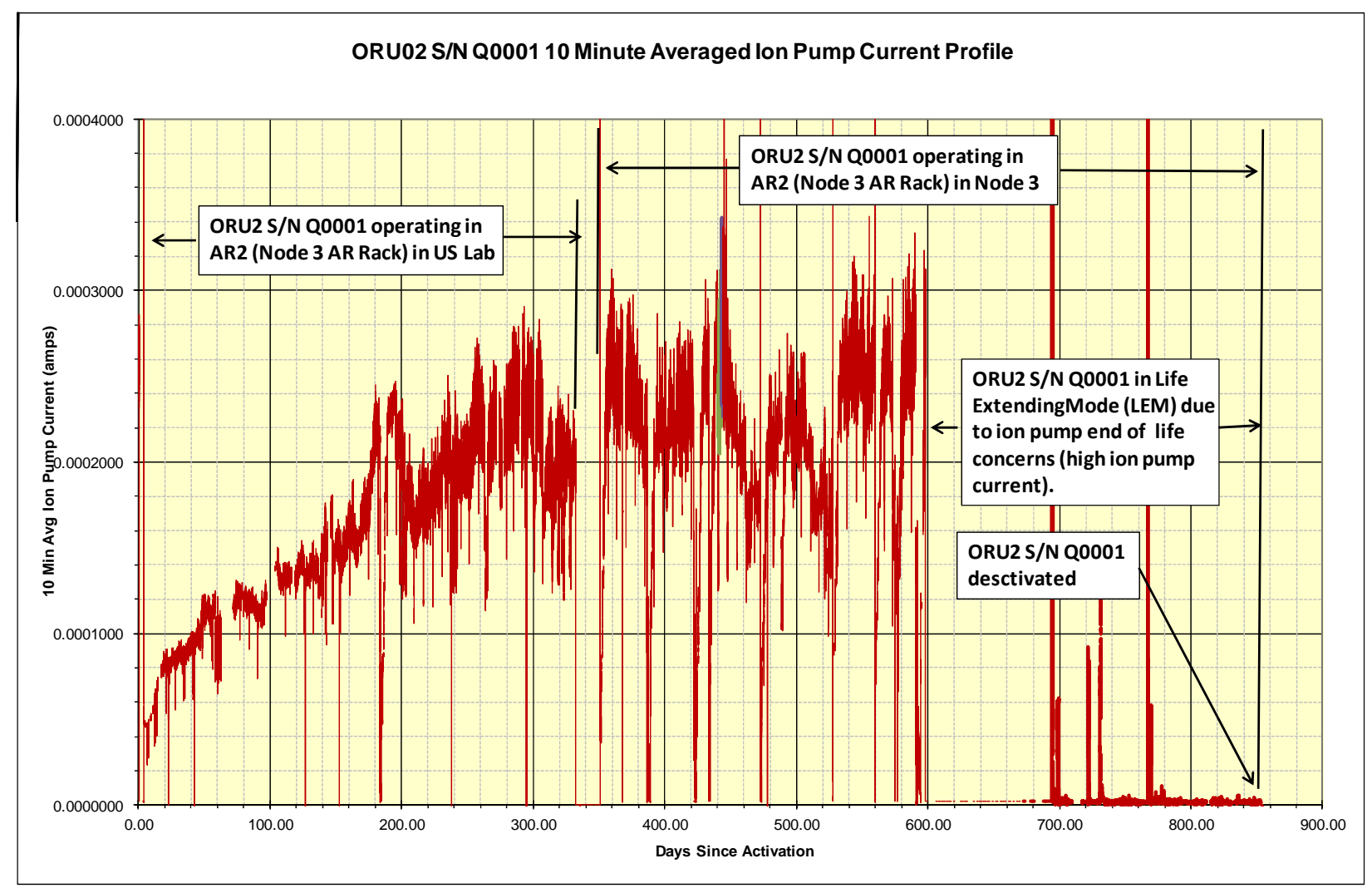

Figure 3: Ion pump current for ORU 02 Q0001.

Figure 4 shows filament current sensor readings FCS01 for Filament 1 of ORU 02 Q0001. Since operation of this ORU 02 was limited by ion pump life, Filament 2 was not operated for a significant duration. FCS01 for Filament 1 trended down from about $145 \mathrm{~mA}$ at start of operation to $130 \mathrm{~mA}$ after one year of operation. The rate of change of FCS01 indicated Filament 1 would have lasted about 1.5 more years if the Ion Pump had supported continued operation. 


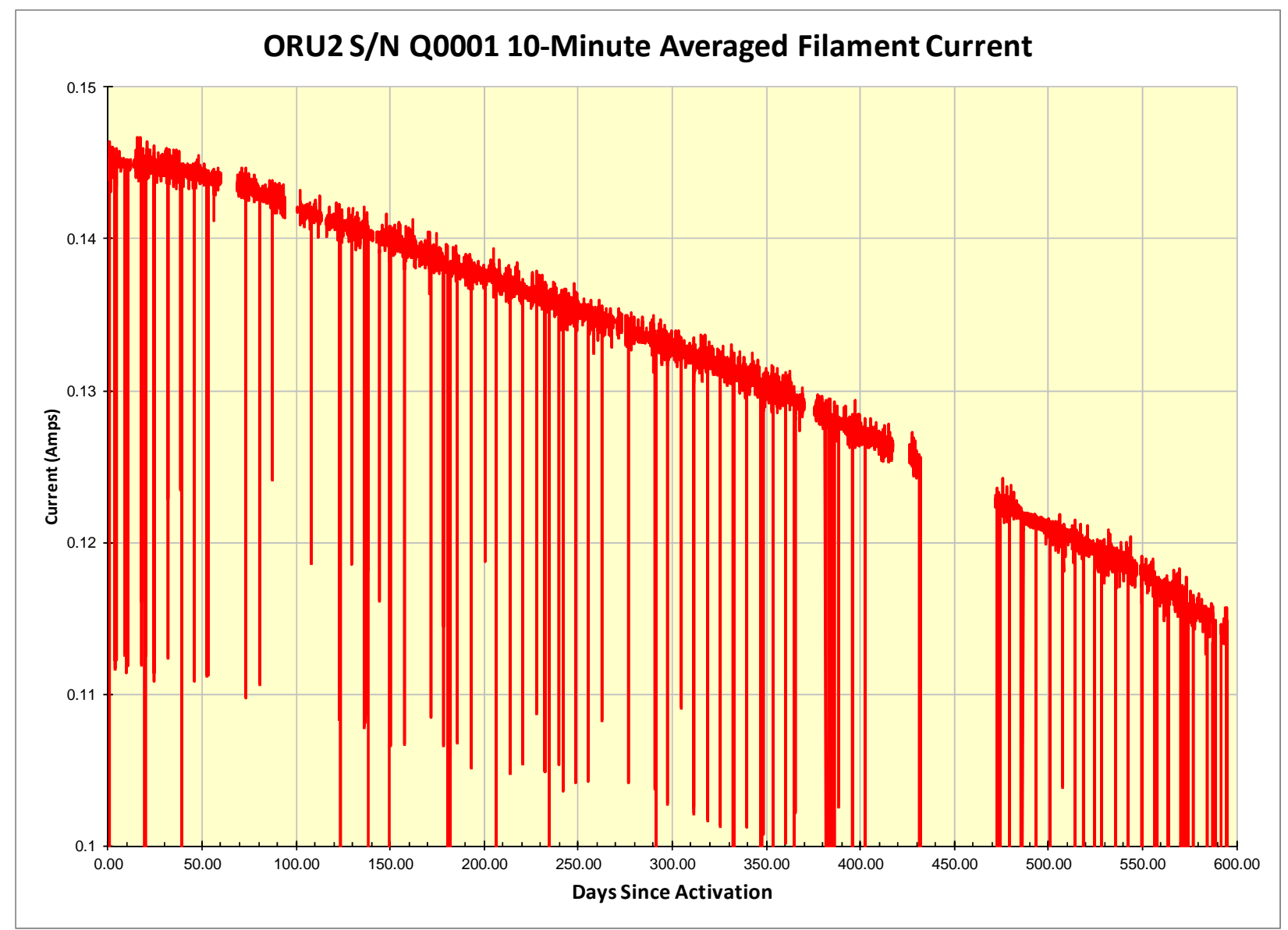

Figure 4: Filament Sensor Reading for ORU 02 Q0001.

\section{B. ORU 02s F0001 and F0003 Performance}

The MCA in AR1 with ORU 01 F0001 and ORU 02 F0003 was activated on 9/13/10. Within a short time several anomalies occurred, implicating both ORU 01 and ORU 02. This was the first on-orbit exercise of the revised CSCI 4.24 firmware, and several of the anomalies were associated with a Data/Control Assembly loss of communications. Concomitantly, ORU 02 experienced a runaway in the Filament \#1 control circuit. Subsequently, the MCA was shut down until the causes of the anomalies could be addressed. On 5/13/11, ORU 01 F0001 with the new firmware was replaced by ORU 01 Q0001 having the previous CSCI 4.18 firmware in order to support the ULF6 mission. ORU 02 F0003 was still installed at this time. The MCA operated nominally for approximately 3 weeks, after which ORU 02 F0003 experienced a failure of its Filament \#2. Subsequently, ORU 02 F0003 was swapped with ORU 02 F0001. ORU 02 F0001 was operated beginning 7/6/11 for approximately 10 days with several filament failures. Initially, it was hypothesized that there might be a failure mechanism inherent to either the MCA chassis or ORU 01. However, real-time ground-based data analysis during operation of ORU 02 F0001 implicated ORU 02 itself. Both ORU 02s F0001 and F0003 were returned to ground and are completing a failure investigation. The results from this failure investigation are expected to drive improved performance in future ORU 02s, and both the results and corrective actions will be reported at a later date.

\section{ORU 02 F0005 Performance}

Subsequent to the failures of ORU 02s F0001 and F0003 on the MCA in AR1, ORU 01 Q0001 with the original firmware was returned to the MCA in AR2, along with ORU 02 F0005. The MCA was activated on 1/28/12 and has been operating nominally since that time.

A plot of normalized ECVs for ORU $02 \mathrm{~F} 0005$ for $\mathrm{CH}_{4}, \mathrm{CO}_{2}, \mathrm{H}_{2}, \mathrm{~N}_{2}$, and $\mathrm{O}_{2}$ is shown in Figure 5. Although the legend lists $\mathrm{H}_{2} \mathrm{O}$, the $\mathrm{H}_{2} \mathrm{O}$ values are off scale. Figure 6 includes $\mathrm{H}_{2} \mathrm{O}$ ECVs by using an expanded scale. The $\mathrm{N}_{2}$ and $\mathrm{O}_{2}$ ECVs are stable thus far. The $\mathrm{CO}_{2}$ ECV shows a trend of about $0.4 \%$ rise in six weeks. If this trend continues, then just before the next calibration of ECVs, the $\mathrm{CO}_{2}$ will be underestimated by $0.4 \%$. For a typical $\mathrm{CO}_{2}$ partial 
pressure of 3 Torr, that would cause an error of 0.012 Torr, which is insignificant to the operation of the Environmental Control and Life Support (ECLS) of the International Space Station (ISS). $\mathrm{CH}_{4}$ also shows an ECV drift of about $0.4 \%$ down. $\mathrm{H}_{2}$ shows a drift up of over $0.8 \%$. Since $\mathrm{CH}_{4}$ and $\mathrm{H}_{2}$ are expected to have very small partial pressures, errors of this magnitude produce very small resulting errors in the partial pressure measurements.

The water ECV has the largest change at about 2.2\%. For a water partial pressure of about 11 Torr, an ECV change of this magnitude could lead to an error in water partial pressure of about 0.24 Torr. The calculation of partial pressure normalizes the partial pressures of all gases such that the total equals the total pressure in the compartment being sampled. Because of this, if one gas is overestimated, then other gases are reduced to compensate. In this case, an error of 0.24 Torr in water would cause compensating errors of approximately -0.18 Torr in $\mathrm{N}_{2}$ partial pressure and -0.05 Torr in $\mathrm{O}_{2}$ partial pressures, for typical ISS atmosphere composition. Both of these side effects are not considered significant. The compensating errors for $\mathrm{CH}_{4}, \mathrm{H}_{2}$, and $\mathrm{CO}_{2}$ are also insignificant.

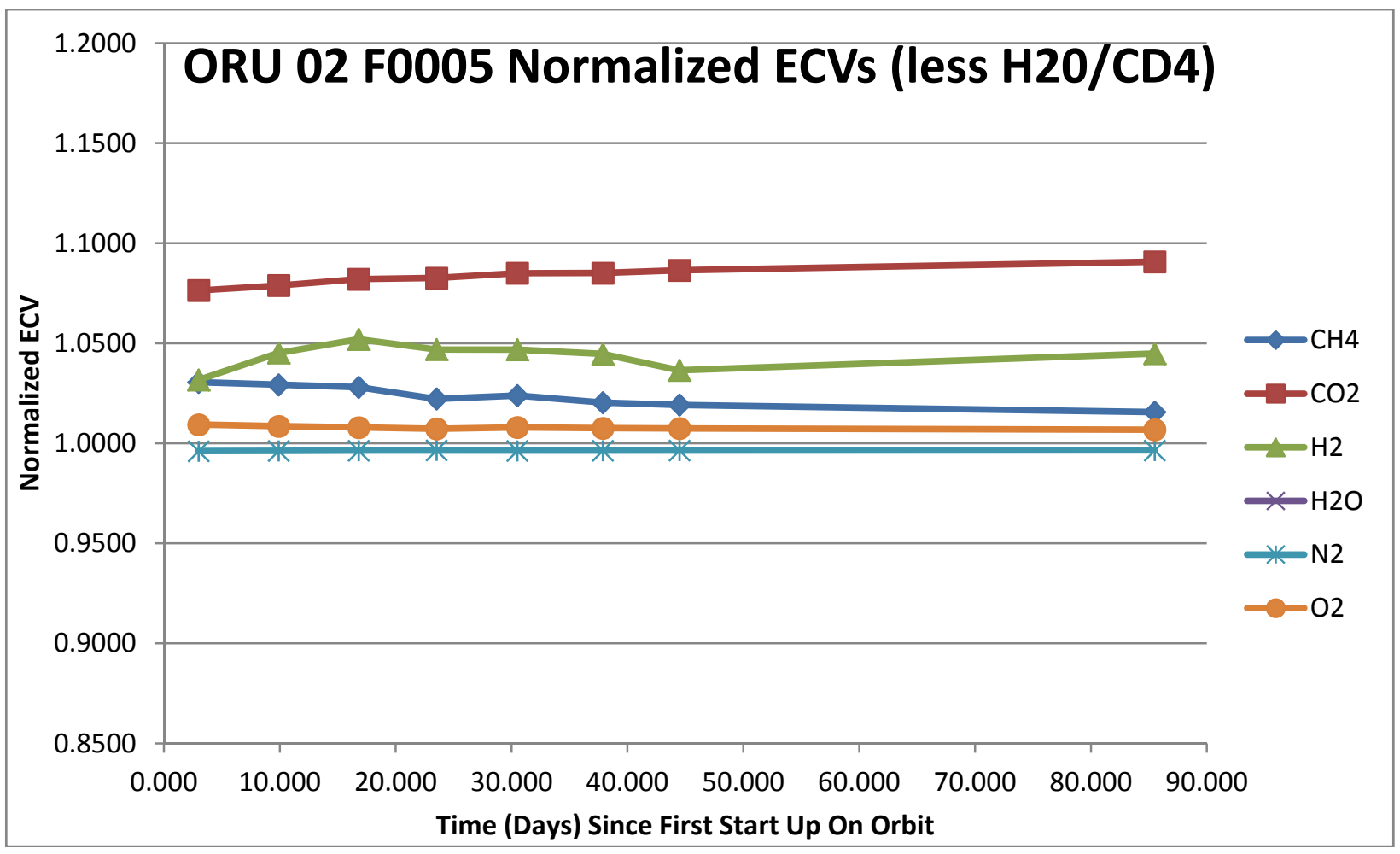

Figure 5: ECV Values for constituents other than $\mathrm{H}_{2} \mathrm{O}$ for ORU $02 \mathrm{~F} 0005$ 


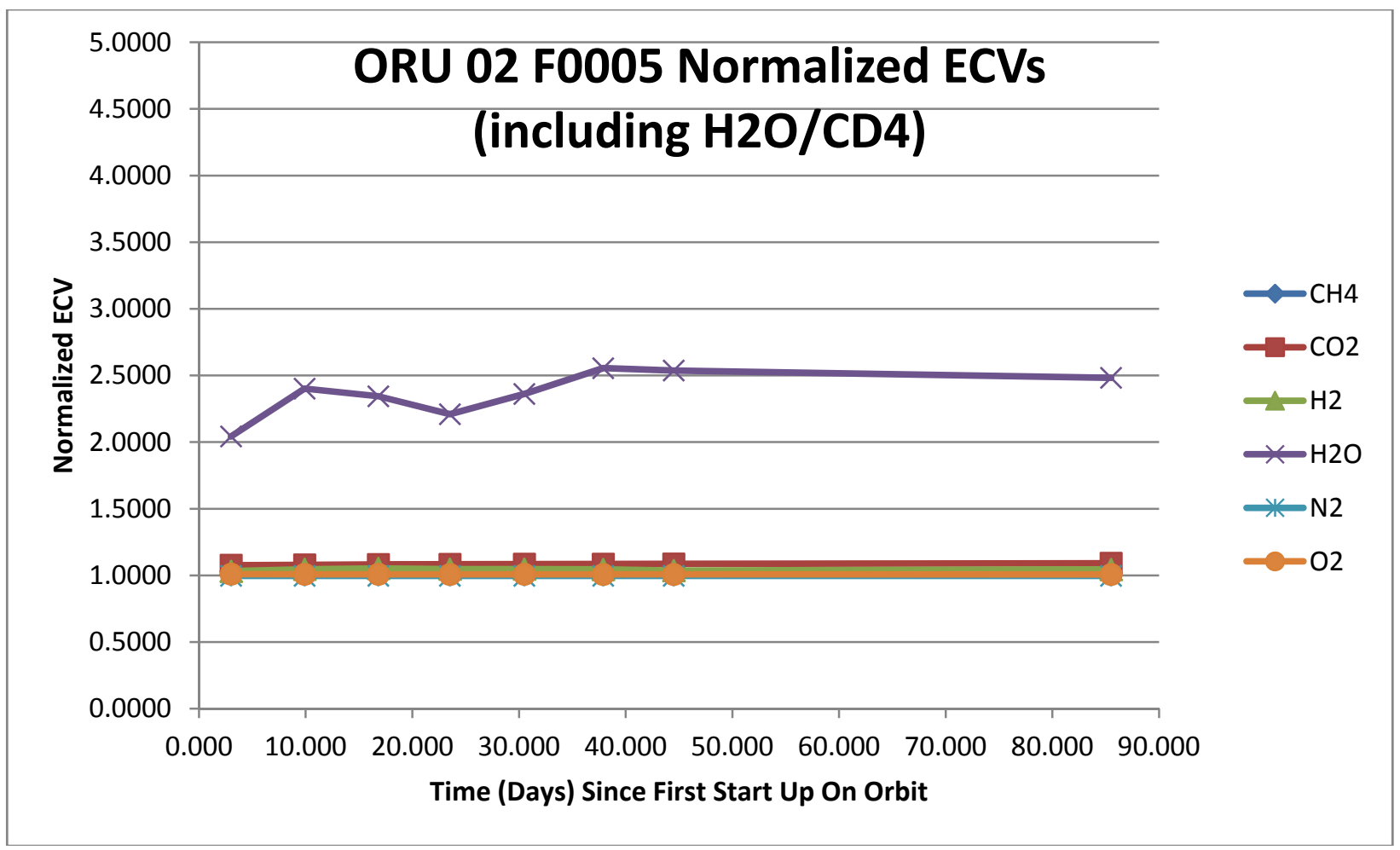

Figure 6: ECV Values for ORU 02 F0005 Including $\mathrm{H}_{2} \mathrm{O}$.

For comparison, the ECV plots for the initial installation of ORU 02 Q0001, the other ORU 02 currently on orbit (degraded spare), are shown in Figures 7 and 8. Neither ORU 02 shows a significant ECV drift rate after the initial 6-week stabilization period on orbit. 


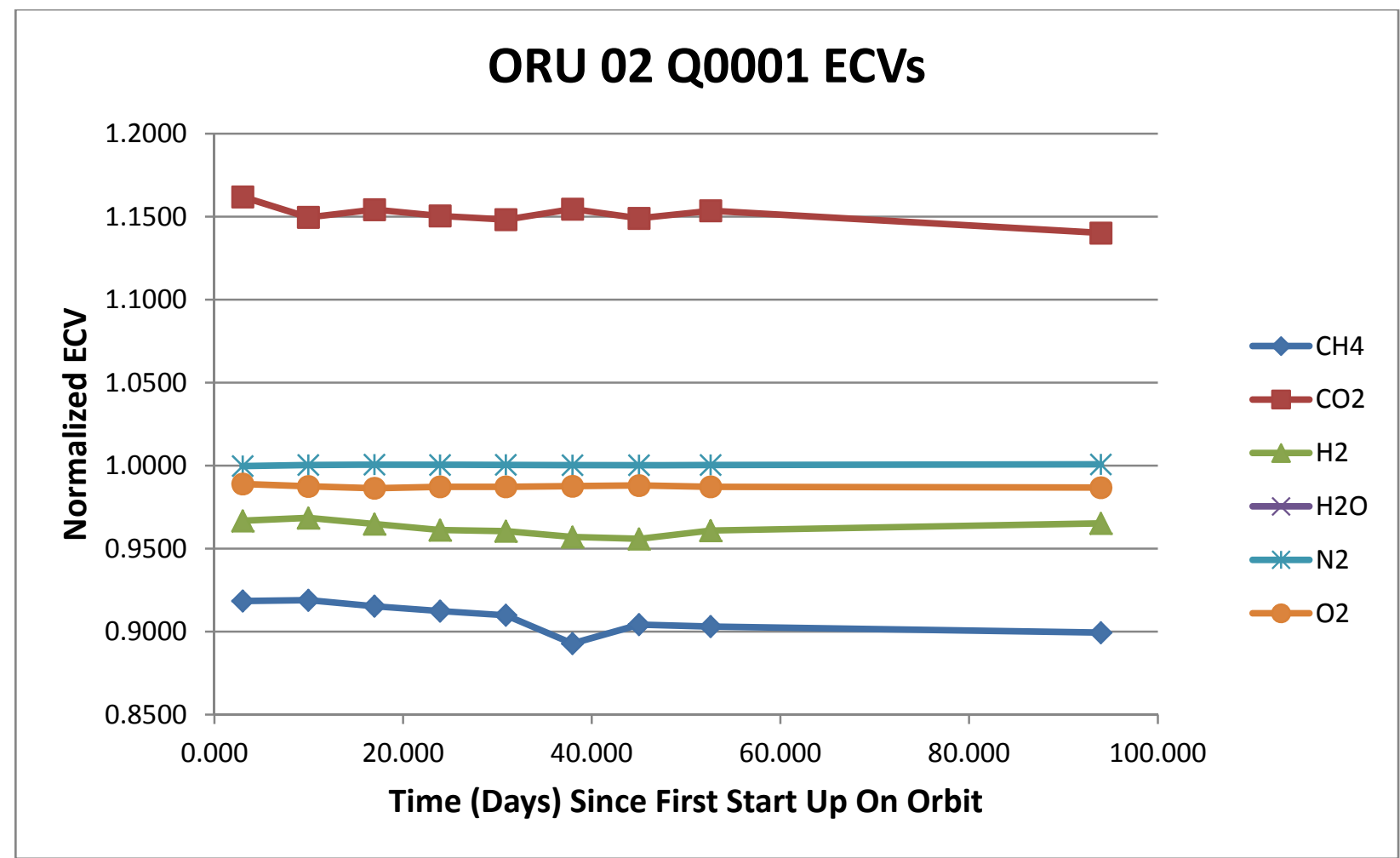

Figure 7: ECV Values for constituents other than $\mathrm{H}_{2} \mathrm{O}$ for ORU $02 \mathrm{Q} 0001$

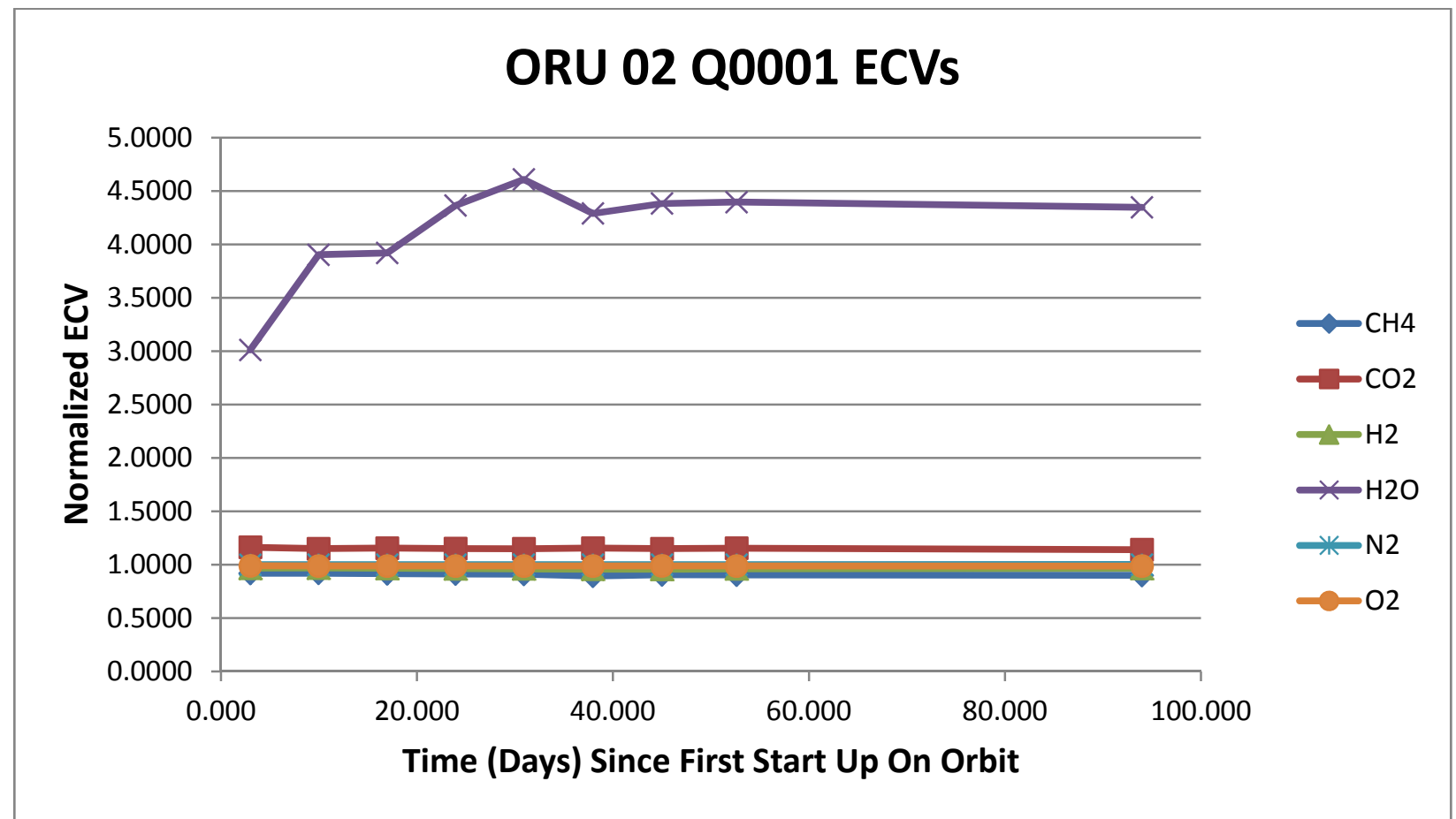

Figure 8: ECV values for ORU 02 Q0001 including $\mathrm{H}_{2} \mathrm{O}$

The ORU 02 ion pump is responsible for maintaining the operational vacuum level of the analyzer, and its degradation over time is the primary factor that limits the useful longevity of an ORU 02 . The ion pump high voltage of F0005 has been lowered about 17 percent compared to previous ion pumps. Ground testing indicates the 
lower ion pump voltage will extend the ion pump life. Since F0005 is the first ORU 02 on orbit with this reduced high voltage, there is keen interest in the effect of the voltage reduction on ion pump life.

Thus far, the ion pump current of F0005 has been more stable than for previous ORU 02s. Figure 9 shows the ion pump current measurements during the first 100 days of operation. The graph shows 10-minute averaged data. Telemetry actually provides an updated value every 10 seconds, so each data point in the graph is the average of 60 readings. The main trace is the ion pump current during normal operation when the pressure at the inlet leak of the mass spec is approximately 336 Torr (6.5 psia). Occasional drop downs by half occur when the MCA is placed in Standby state or another state with no sample valve open. At such times, the pressure at the inlet leak drops to about 170 Torr. From February 7 to May 5 (88 days), the current rose from $68 \mu$ Amps to $71 \mu$ Amps.

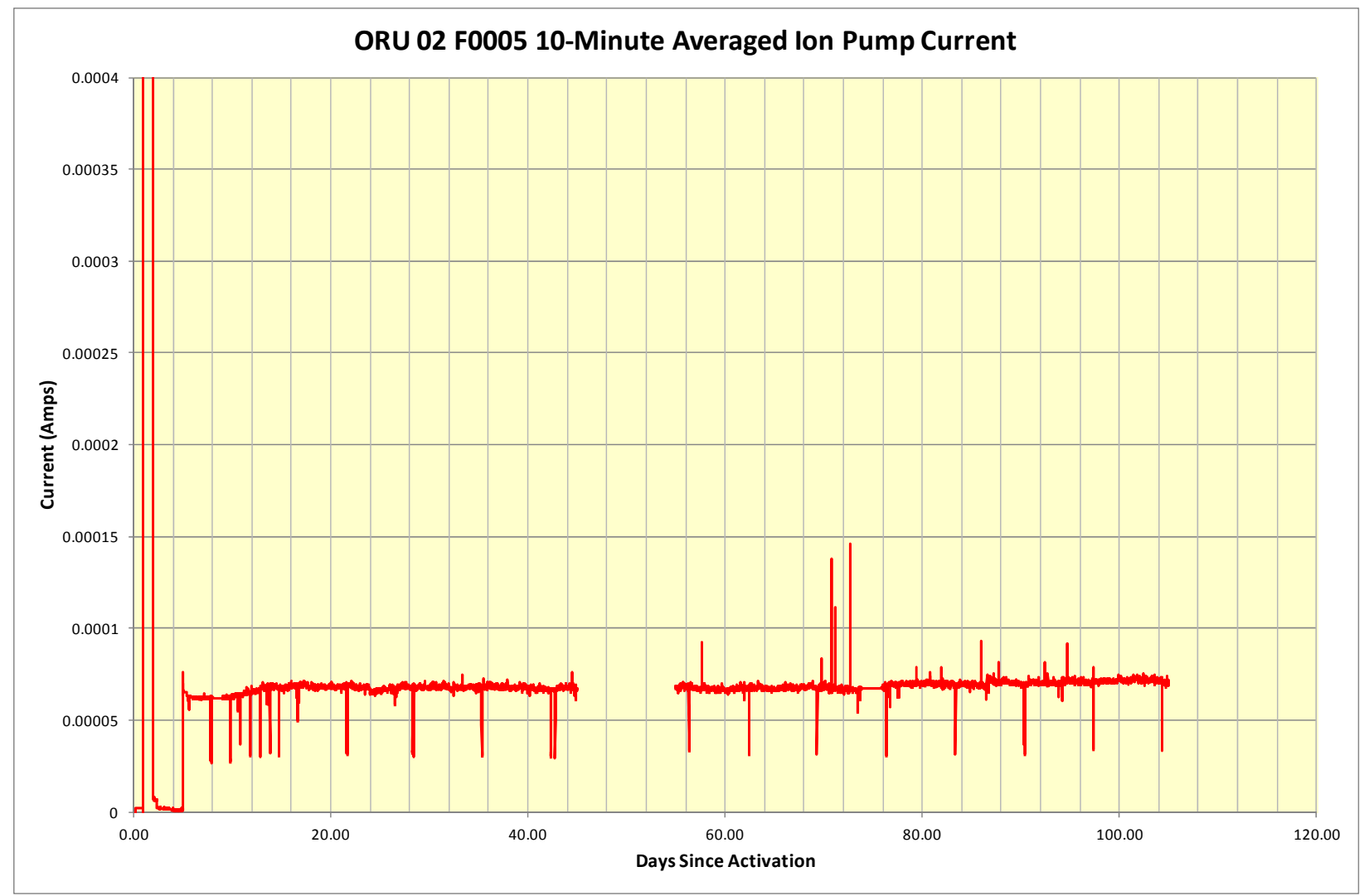

Figure 9: Ion Pump Current for ORU 02 F0005

In contrast to the performance of F0005, the ion pump current trend for ORU 02 Q0001 is shown in Figure 10. After the initial stabilization, the ion pump current rose from about $75 \mu$ Amps on day 15 to $130 \mu$ Amps on day 105 . A gradual rise of ion pump current has been typical of the performance of ion pumps in the past, with rates varying from $20 \mu$ Amps in 90 days to $100 \mu$ Amps in 90 days. The rise in ion pump current of ORU 02 F0005 by only $3 \mu$ Amps in 90 days is a considerably lower rate. 


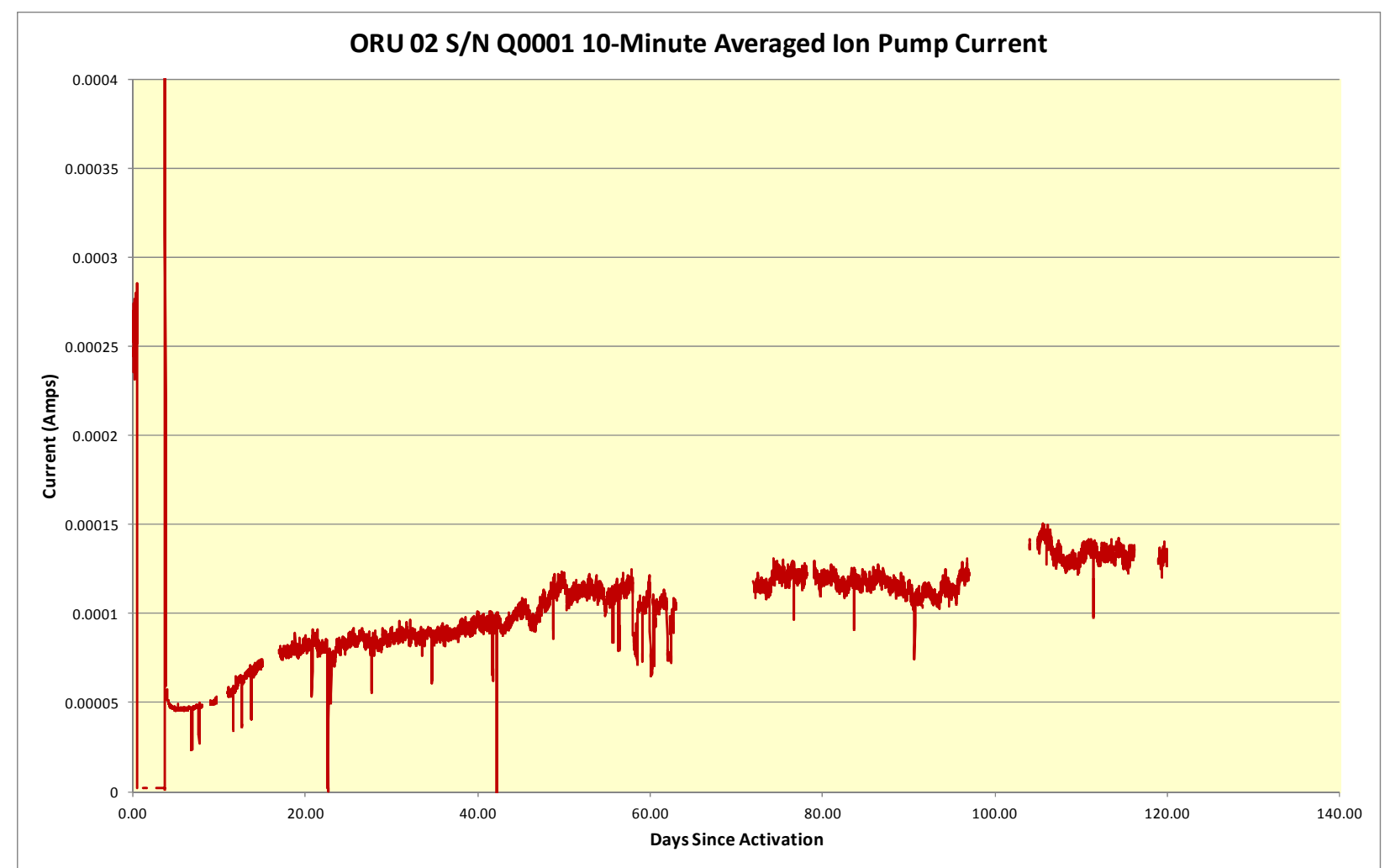

Figure 10: Ion Pump Current for ORU 02 Q0001 covering the same time-span as ORU 02 F0005.

Filament 1 performance in ORU 02 F0005 is performing nominally. Except for about two minutes of operation during Built-In Testing, Filament 2 has not been operated on orbit. Figure 11 shows the filament current measurements for Filament 1. Filament current is expected to trend down gradually. The filament current behavior shown in the figure is typical for filaments and is useful for estimating the remaining life of a filament. Filament current on 4/13/12 was 0.12914 amps (average of all readings for the day). Filament current on 5/5/12 (22 days later) was $0.12784 \mathrm{amps}$ (average of all readings for the day). The Slope $=-5.912 \times 10^{-5} \mathrm{amps} /$ day. If the filament is usable down to 0.100 amps, filament life remaining from $5 / 5 / 12=(0.1278-0.100)$ amps $/ 5.912 \times 10^{-5} \mathrm{amps} /$ day $=$ 470 days. This is a respectable filament duration. (Note: The MCA filament current sensor FCS01 reads the current through the primary of a transformer. The actual current through the filament is closer to one amp.) 


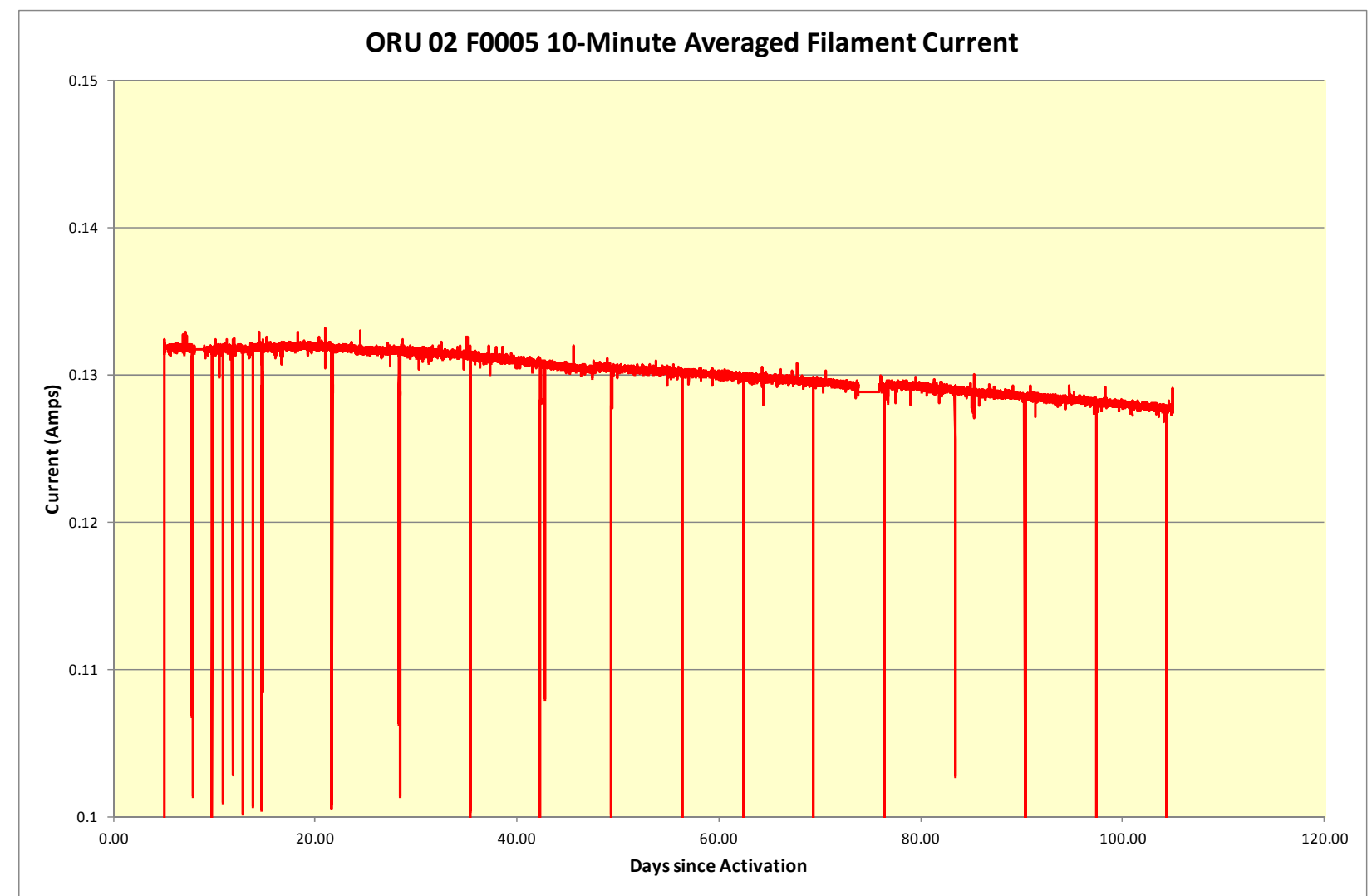

Figure 11: ORU 02 F0005 Filament Current Sensor (FCS01) Readings for Filament 1.

\section{ORU 08 Performance}

\section{A. ORU 08 Q0001 Performance}

In late 2011, there was a concern that the ISS might need to be de-crewed. It was decided that if the ISS were decrewed, the capability to operate the MCA periodically to check ISS atmosphere composition should be retained. Since the manual valve in VGA serial number Q0001 had to be kept closed to preserve calibration gas, the MCA could not be calibrated without the crew present. To restore capability to calibrate the MCA from the ground without crew intervention, Verification Gas Assembly (VGA) Q0001 was replaced by VGA serial number F0001 which had previously been installed in the MCA in AR2.

During a checkout of the capability to operate and calibrate the MCA in AR2 from the ground, a problem was identified with the timing of the Node 3 Vacuum Vent Valve, which provides capability to evacuate the mass spectrometer should the mass spectrometer pressure be too high for a normal startup. If mass spectrometer pumpout is required, this valve should be opened 5 minutes prior to sending the MCA startup command and remain open until the MCA opens its internal solenoid valve exposing the mass spectrometer to vacuum and completes its startup sequence as indicated by reaching the "Standby" state. During the checkout, however, the Node 3 Vacuum Vent Valve was opened 5 minutes prior to startup, but closed when the MCA startup command was sent. Thus, when the MCA's internal solenoid valve opened during the startup sequence, there was insufficient vacuum to support mass spectrometer activation and the MCA went to the Fail state. This checkout was the first time that a Startup with pumpout was attempted in Node 3. The problem was traced to an error in the ISS software code that commands the MCA. The MCA was successfully started by manually overriding the Node 3 Vacuum Vent Valve open.

\section{Conclusion}

Recent on orbit experience with ORU 02 has shown mixed performance. ORU 02s Q0001 and F0005 have thus far operated well, while ORU 02s F0001 and F0003 experienced premature on-orbit failures. The premature failures are under review. The ion pump current for ORU 02 F0005 is rising more slowly than for past ion pumps. This is attributed to the incorporation of reduced gas inlet flow to the ion pump and to lower ion pump high voltage. These 
features are expected to increase the absolute lifetime of the ion pump and mitigate the ion pump's historical role as the primary life-limiting component of ORU 02s. The filament current for ORU 02 F0005 is declining at a rate consistent with about 1.5 years of total life. Assuming the second filament performs as well, the data support a prediction of approximately three years total life for ORU 02 F0005.

Trending of electrometer correction values continues to provide the basis for prediction of drift in MCA-measured partial pressures. This, in turn, has enabled the interval between MCA full calibrations to be extended to conserve calibration gas without any loss of accuracy. As MCA operational experience continues to be accumulated, trending of these and other parameters will facilitate use of the MCA with increasing efficiency and effectiveness. The stability of ORU 02 F0005 atmosphere composition measurements is consistent with previous MCA performance.

\section{References}

${ }^{1}$ Gardner, B. D., Erwin, P. M., Thoresen, S. M., Granahan, J. and Matty, C., “International Space Station Major Constituent Analyzer On-orbit Performance," 40 ${ }^{\text {th }}$ International Conference on Environmental Systems, Barcelona, Spain, 2010.

${ }^{2}$ Gardner, B. D., Erwin, P. M., Lee, W. T., Tissandier, A. M. and Thoresen, S. M., "Improving the Measurement Accuracy of Water Partial Pressure Using the Major Constituent Analyzer," 39 $9^{\text {th }}$ International Conference on Environmental Systems, Savannah, GA 2009.

${ }^{3}$ Thoresen, S. M., Steiner, G. and Granahan, J., “International Space Station (ISS) Major Constituent Analyzer (MCA) On-orbit Performance,” $38^{\text {th }}$ International Conference on Environmental Systems, San Francisco, CA 2008.

${ }^{4}$ Steiner, G., Thoresen, S. M., Reysa, R. and Granahan, J., “International Space Station (ISS) Major Constituent Analyzer (MCA) On-orbit Performance,” $36^{\text {th }}$ International Conference on Environmental Systems, Norfolk, VA 2006. 